" الكتابات و النقوش الأثرية بمقبرة الخديوي إسماعيل وأمه خوشيار هانم

بجامع الرفاعي "'" در اسة تاريخية حضيارية "

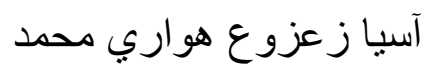

المقدمة

قامت النقوش الكتابية بدور مهم بعدّها عنصرا زخرفيا وتسجيليا علي العمائر الإسلامية منذ

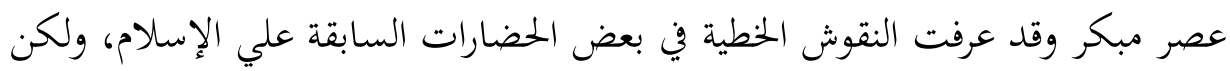

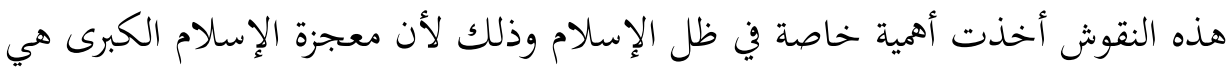

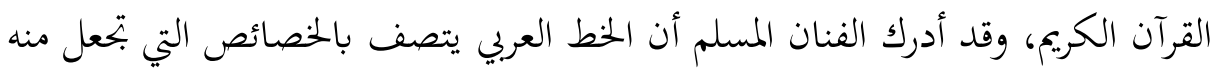

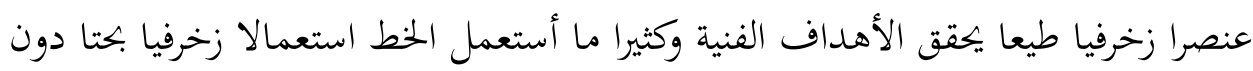

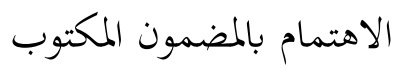

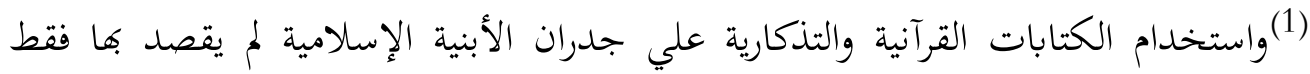

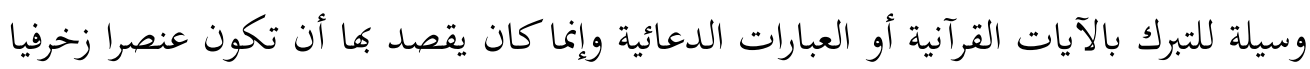

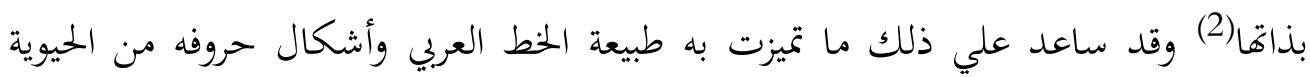
بضضل ما فيها من الموافقة والمرونة والمطاوعة وما فيها من قابلية المدور الرجع والاستدارة والتزوية والتشابك والتداخل وما فيها من اختلاف الوصل والفصل منا هيأ لها فرص التطور والزخرفة

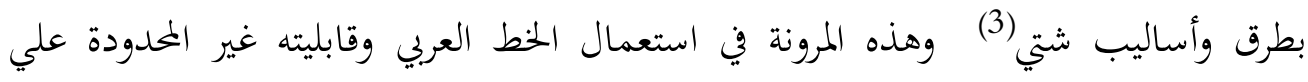

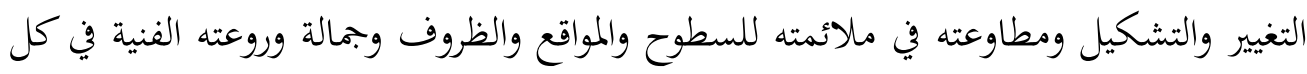

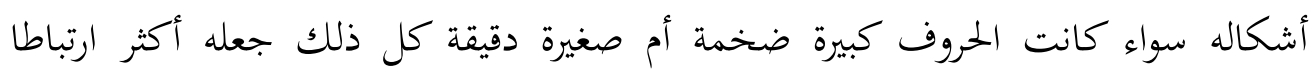

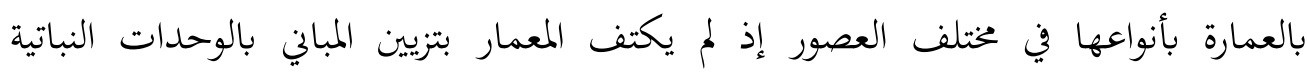
والهندسية بل أضاف لها عنصر الحطط العربي .

تتضمن هذه النقوش في بجملها نصوصا تأسيسية تحوي اسم المنشئ وألقابه ووظائفه واسم

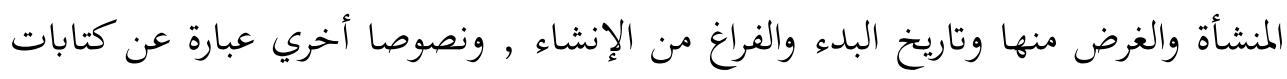


" الكتابات والنقوش الأثرية بمقبرة الحديوي إسماعيل وأمه خوشيار هانم بجامع الرفاعي "

تتضمن نصوصا قرآنية أو أحاديث نبوية أو أدعية أو أقوال مأثورة أو قصائد وأبيات شعرية

إلي غير ذلك من النصوص التي كتبت علي العمائر (4).

وقد تعددت النقوش الكتابية التي استخدمت في تسجيل الأحداث في العصور الإسلامية المختلفة وانتشرت انتشارا واسعا في جميع ربوع البلدان الإسلامية وتنوعت في أغراضها والمدف المنشود منها فنجد النقوش الصخرية والنقوش الشاهدية ونقوش الإنشاء والتعمير والنقوش الإعلامية ونقوش السكة ونقوش الفنون التطبيقية والزخرفية (5).

وتتمثل أهمية تلك النقوش في تصحيح بعض الأخطاء الشائعة وحسم الخلاف بين المؤرخين بل التأكيد علي صحة ما ورد بالمصادر التاريخية(6), فهي تمدنا بمعلومات موثقة لا جدال فيها تساعد علي إماطة اللثام عن الكثير من الجوانب الغامضة في بعض العصور والفترات , وغير ذلك تعتبر تلك النصوص أهم وأصدق مصادر كتابة التاريخ والملاذ الآمن والدليل الدامغ للحفاظ علي حقوق المنشئين والمجددين والمرمين وإعطاء كل ذي حق حقه . وقد أدت هذه النقوش دورا كبيرا في الحفاظ علي أسماء أهل الصنعة من خطاطين ونقاشين ومزخرفين وحرفيين علي مختلف مسمياهم وحرفهم بالإضافة أها تمدنا بمعلومات موثقة عن

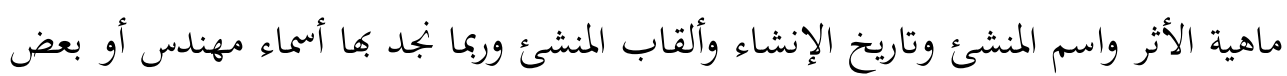
الصناع الذين شاركوا في إتمام العمل الفني . كما أمدتنا نقوش وكتابات تلك البحث من خلال تحليل مضامينها بكثير من الألقاب والتواريخ فضلا عن أنواع الخطوط مثل الخط الكوين الذي كان له السبق في العصر الفاطمي, ثم حل بدلا منه الخط الثلث في العصر المملوكي ثم الخط النستعليق الذي ساد في العصر العثماني , بالإضافة إلى توقعيات الخطاطين والتعرف علي أسمائهم ومن خلالها نتمكن من معرفة أوقات الازدهار والركود في الناحية الفنية لتلك العصر.

وقد تم تقسيم البحث إلي فصلين , حيث يتناول الفصل الأول : الدراسة الوصفية لمقبرة الخديوي إسماعيل وأمه السيدة خوشيار منشئة الجامع بينما يتناول الفصل الثاني : الدراسة

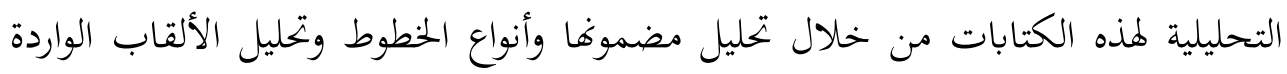


بالنصوص والمادة الخام التي نفذت عليها هذه الكتابات , هذا بالإضافة إلى تدعيم البحث ببعض الصور الفوتوغرافية من تصوير الباحثة .

\section{الخديوي إسماعيل}

هو إسماعيل بن إبراهيم بن محمد علي ولد في قصر المسافر خانه بحي الجمالية بالقاهرة يوم

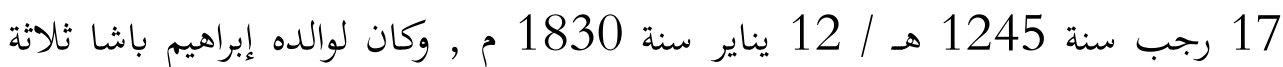
أولاد أوسطهم إسماعيل والأكبر أحمد رفعت والأصغر مصطفي فاضل وهما أخوين غير شقيقين لإسماعيل (7) (1) , وكان إسماعيل باشا يانع الجسم متلنئ قوي البنية ربع القامة عريض الجهة كثيف اللحية والشارب والحاجبين متوسط الطول مستدير الوجه(8) (2). وقد عني أبوه بتربيته فتعلم مبادئ العلوم واللغة العربية والتركية والفارسية وقليل من الرياضيات والطبعة ثم أرسله أبوه إلي فيينا عاصمة النمسا ليعالج بها من رمد صديدي وكان عمره أربعة عشر سنة فقضي بها عامين ثم انتقل الي باريس ليلتحق بالبعثة المصرية الخامسة التي عرفت

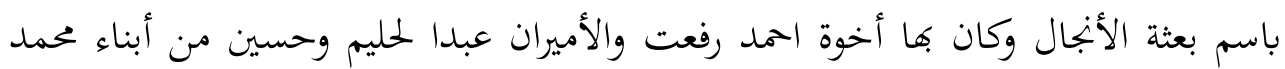
علي فنال في باريس حظا من العلوم الهندسية والرياضية والطبيعة وأتقن اللغة الفرنسية وبهرته باريس وما فيها من جمال وروعة وفتنه وبهذا بدأ ميوله الفرنسية التي لازمته طوال حياته والتي جعلته يسعي ليجعل من القاهرة باريس الثانية عاد إسماعيل إلي مصر في عهد ولاية أبية إبراهيم باشا وملا مات إبراهيم وخلفه عباس الأول شعر إسماعيل وإخوته بكراهية عباس لهم ثم مات محمد علي وزاد الحصام بين عباس وبقية الأمراء فارتحل إسماعيل إلي الأستانة وعينه السلطان عبد المجيد عضوا بمجلس أحكام الدولة العثمانية وانعم علية بالباشوية ولم يعد إسماعيل الي مصر إلا بعد مقتل عباس وفي عهد عمة سعيد لقي منه إسماعيل عطفا شديدا وعهد إلية برئاسة بجلس الأحكام وأوفده سنة 1271 هـ/ 1855 م في مهمة سياسية لدي نابليون الثالث إمبراطور فرنسا , وقد جعلة سعيد نائبا عنه ( قائم مقام ) أثناء غيابة عن مصر مرتين الأولي أثناء زيارة سعيد لسوريا سنة 1276 هـ/ 1859 هـ 185 م والثانية أثناء

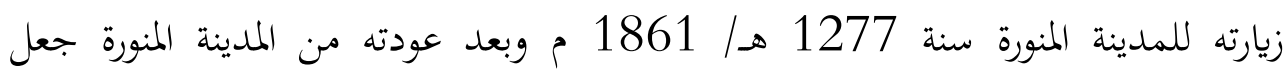


" الكتابات والنقوش الأثرية بمقبرة الحديوي إسماعيل وأمه خوشيار هانم بجامع الرفاعي "

إسماعيل سردار للجيش المصري وعهد إليه إخماد فتنة بعض القبائل في السودان فقام إسماعيل

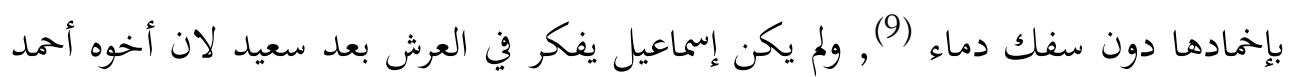
رفعت كان أكبر منه وهو ولي العهد ولكن أخاه هذا لقي حتفه في حادث قطار حيث سقطت العربة التي تنقله في النيل عند كفر الزيات وغرق أثناء عودته من الإسكندرية سنة

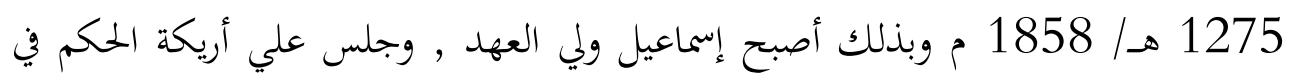

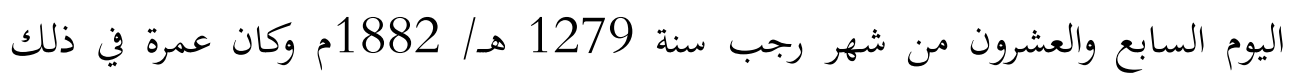
الوقت اثنين وثلاثين سنة وتلقب إسماعيل باشا رسميا من الباب العالي بلقب خديوي وقد وفق في الحصول من تركيا علي أقصي ما يمكن من الحقوق والمزايا كي يصل بمصر إلي الاستقلال التام فهذه نزعة مجيدة تدل علي شدة حبة لمصر واتجهت همته إلي توسيع أملاك

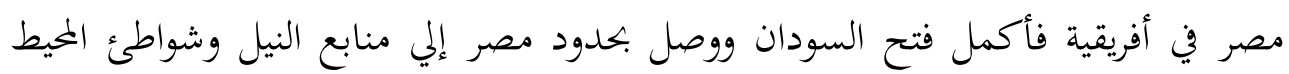
الهندي اي إلي حدودها الطبيعية وعني بقوة الباد الحربية بتنظيم الجيش وإنشاء المدرسة الحربية العالية وتسليح الجند بأحدث الأسلحة وتزويد الحصون والقلاع بالمدافع الضخمة ووجه أيضا همته إلي إهاض البحرية المصرية حربية كانت أو تحارية فرفع علم مصر علي مياه البحر الأبيض المتوسط والبحر الأحمر , كما اهتم الخديوي إسماعيل بالعلم والأدب وإنشاء المدارس العالية والمعاهد العلمية وإرسال البعثات وقد برز في عصره كثير من العلماء والأدباء منهم رفاعة الطهطاوي وعلي باشا مبارك وغيرهم كما انتشرت الصحف التي أدت إلي تنوير الرأي العام كما قان بأعمال العمران مثل فتح الترع وإقامة الجسبور والعناية بالزراعة وغيرها من المجالات كما قام بتجميل القاهرة والإسكندرية ليجعلها تماثل أعظم مدن أوربا وأمر بمد فئل الطرق المستقيمة (10).

واشتهر بمشاريعه العمرانية والثقافية والغا الرق وبني مدينة الإسماعيلية والتوفيقية وعابدين وميدان الأوبرا وغيرها, وكان إسماعيل باشا أية في الذكاء والفهم وسرعة الخاطر وقوة التركيز وقوة الشخصية وبجانب الحسنات يوجد الجانب السيئ في شخصية إسماعيل وهو بزخه وإسرافه وعدم تقدير العواقب وضعفه أمام الملذات والشهوات مما أدي إلي كثرة الاقتراض بالربا الفاحش ووقوع البلاد في الديون والتعهدات مما أدي أيضا إلي أثقال عاهل الأهال 
بمختلف الضرائب والجبايات لتسديد فوائد الديون المتراكمة ولأنفاق علي المشروعات الكبيرة وسد النفقات الخاصة به (11), في أواخر عهده ونتيجة للأزمة المالية زاد ضغط الدول الأوربية وتدخلها في شئون البلاد الداخلية من إنشاء صندوق الدين إلي فرض الرقابة الثنائية علي مالية مصر تم تعيين وزيرين أوروبيين في الحكومة المصرية ولما أحس إسماعيل بثقل وطئه هذه إنياء الدول وما تفرضه عليه من قيود سعي للتخلص من ذلك اعتمادا علي مساندة الوطنيين ولكن الدول الأوروبية وخاصة إنجلترا وفرنسا تم ألمانيا سعت لدي من دي الباب العالي واستصدرت

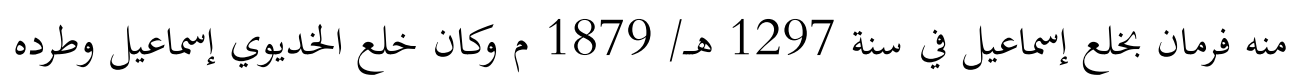

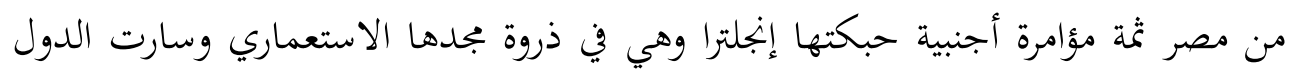

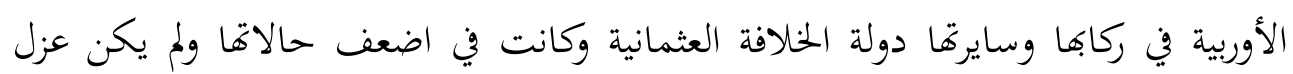
إسماعيل بسبب عجزة عن تسديد الديون كما أشاعوا ولكن إنجلترا هي التي كانت تسعي إلى إعلان إفلاس مصر تمهيدا لاحتلاها والسيطرة علي قناة السويس مفتاح بلاد الهند وفي سنة 1305 هـ/ 1888 م انتقل الخديوي إسماعيل إلي الأستانة وقام بقصر ( أمرجياني ) علي

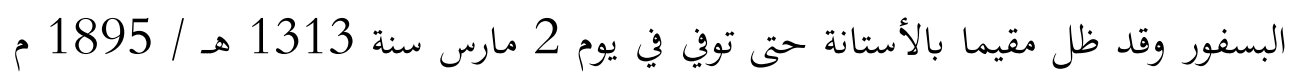

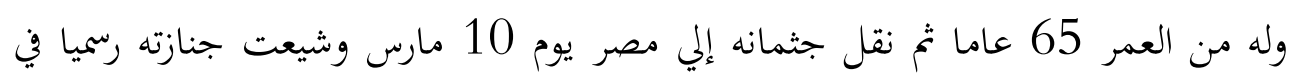
الإسكندرية ثم القاهرة حيث دفن في مسجد الرفاعي الذي أوصي بأن يدفن فيه(12).

\section{كتابات مقبرة الحديوي إسماعيل}

وأمه السيدة خوشيار هانم بجامع الرفاعي (13)

تقع هذه المقابر بالجهة الشمالية الشرقية بجامع الرفاعي المواجهة لمدرسة السلطان حسن بميدان الرفاعي

أسم المنشئ : خوشيار هانم والدة الخديوي إسماعيل

تاريخ الإنشاء : 1286هـ/ 1869 م 
" الكتابات والنقوش الأثرية بمقبرة الحخديوي إسماعيل وأمه خوشيار هانم بجامع الرفاعي "

\section{كتابات تركيبة الحخديوي السماعيل 1312هـ / 1894 م}

رقم 5 بالحجرة رقم 6 , وهذه التركيبة تتكون من ثلاث مستويات من الرخام يعلوها من الجهة الجنوبية الغربية شاهد قبر اسطواني كما يعلو الجهة الشمالية الشرقية شاهد قبر مستدير

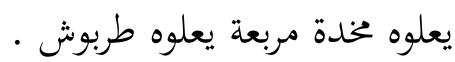

\section{كتابات شاهد القبر من الناحية الجنوبية الغربية :-}

عبارة عن شاهد اسطواني من الرخام بالحفر البارز بالخط الثلث والكتابات منفذة بالتذهيب

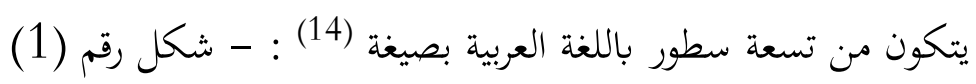

$$
\text { تاريخ ولادني }
$$

بيت إبراهيم طوي له نور إسماعيل 1244

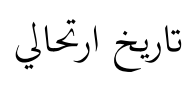

إن الخلديو عزيز مصر قد ثوي

في روضة النور البديع الزاهي

صبت عليه سحائب من رمة

بشفاعة الداعي عظيم الجاه

والحور والوالدان قالت أرخوا

طاب العلا إسماعيل ضيف الله 1312

كتابات شاهد القبر من الناحية الثمالية الشرقية :_ (15)

كل من عليها فان هذا ضريح مصر وسما بين عاجله لالسكن الجنات الدار قلت هو قيل الودود تفضله إسماعيلا 


\section{كتابات المستوي الثاني بالتركيبة :-}

عبارة عن أربعة لوحات مستطيلة الشكل من الرخام الأبيض بالخط الثلث البارز من سطر

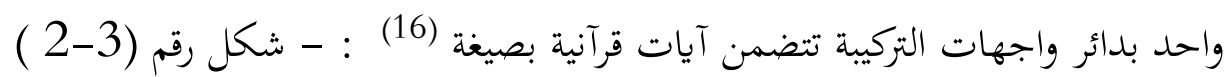

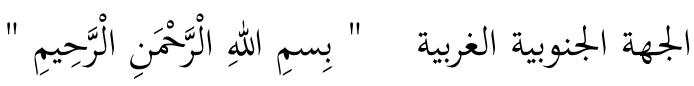

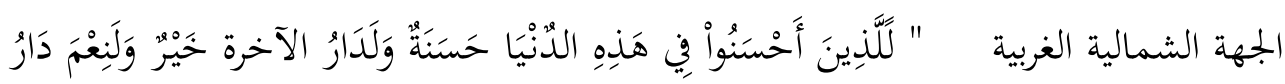

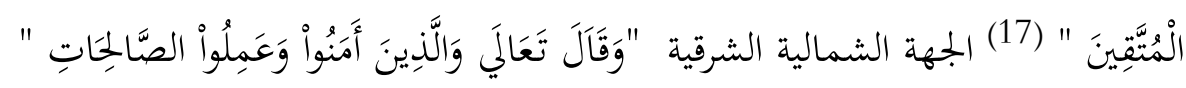

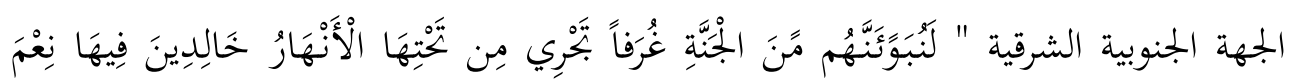

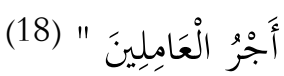

\section{كتابات المستوي الثالث بالتركيبة :-}

عبارة عن دوائر بها نقوش كتابية علي جانبيها أنصاف دوائر بها زخارف نباتية من الرخام الأبيض والأسود بالحفر البارز بالخط الكوفي ذو الأرضية النباتية من سطر واحد تقرأ (19) :

الجهة الجنوبية الغربية " إسماعيل باشا خديوي مصر "

الجهة الشمالية الغربية " محمد رسول الله صادق الوعد الأمين "

الجهة الشمالية الشرقية " توفي عام اثنتي عشر وثلاثمائة ألف "

الجهة الجنوبية الشرقية " لا إله إلا الله الملك الحق المبين "

كتابات تركيبة خوشيار هانم أم الخديوي (20) 1303 هـ / 1885 م

رقم 2 بالحجرة رقم 6 وهي تركيبة رخامية من مستويين مقامة علي قاعدة رخامية يبلغ طولها

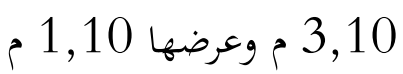

مزخرفة بزخارف هندسية ونباتية بارزة علي شكل مربعات ومستطيلات نقش بداخلها آيات

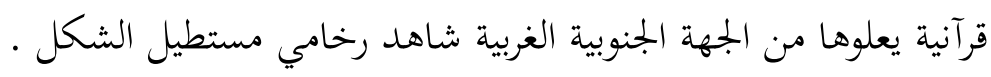


" الكتابات والنقوش الأثرية بمقبرة الحديوي إسماعيل وأمه خوشيار هانم بجامع الرفاعي "

\section{كتابات شاهد القبر :-}

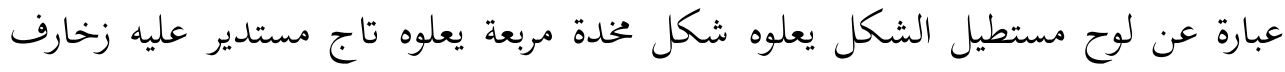

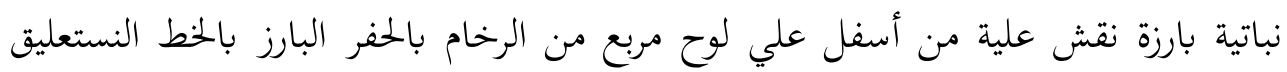
الفارسي يتكون من أربع سطور كل سطر من بحرين يفصل بين كل سطر والأخر خط أفقي وأسفل النص مستطيل صغير يحوي أسم الخطاط والتاريخ وأعلي الشاهد نصف دين دائرة تحوي بندي

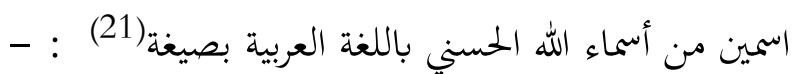
هو الحي الباقي

$$
\begin{aligned}
& \text { أم الخديوي إسماعيل أنوارا } \\
& \text { هذا ضريح كسته شمس دولتنا } \\
& \text { وقد سقاه نمير الفضل مدرارا } \\
& \text { قد صار كالفلك الأعلى وزاد سنا } \\
& \text { وقد غدا لكمال الفوز تذكارا } \\
& \text { بالحور والنور قد حفت جوانبه } \\
& \text { حي الالى محل حاز خشيارا }
\end{aligned}
$$

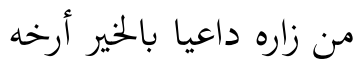

$$
\begin{aligned}
& \text { 111216 } 167968 \text { راقمه عبد الكريم فايق سنة } 1303 \text { هـ } \\
& \text { كتابات المستوي الأول بالتركيبة :- }
\end{aligned}
$$

عبارة عن مربعات نقشت بداخلها آيات قرآنية بالخط الثلث الجلي البارز والكتابات منفذة

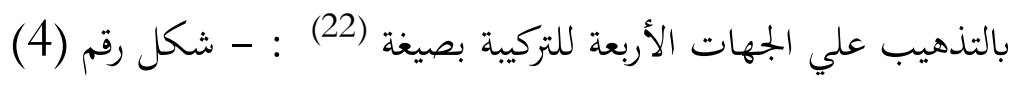

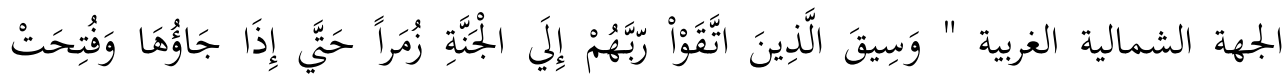
أَبَوَابُهُا

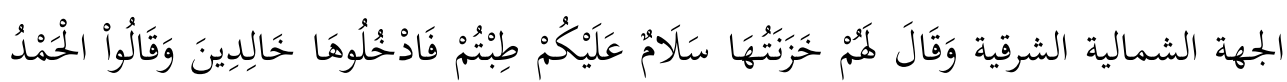

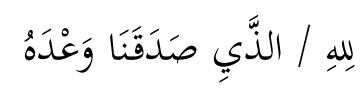

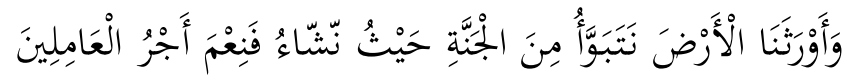




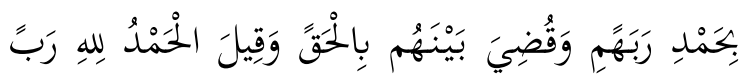

الجهة الجنوبية الشرقية

الْعَالَمِينَ

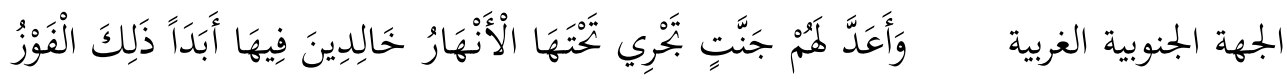

الْعَظِيمُ " (23)

\section{كتابات المستوي الثالي بالتركيبة :-}

عبارة عن مستطيلات ومربعات نقشت بداخلها آيات قرآنية بالخط الثلث الجلي البارز

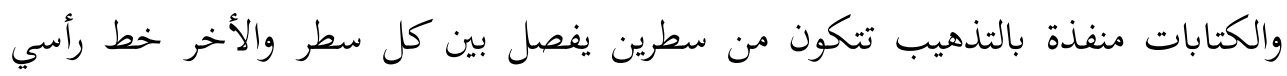

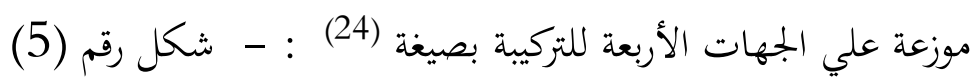

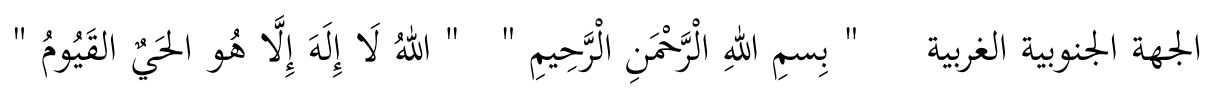

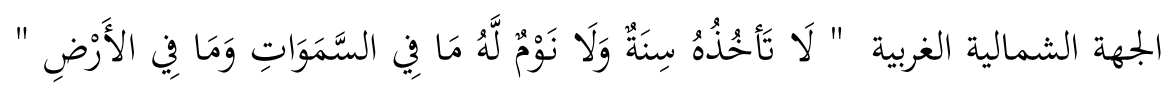

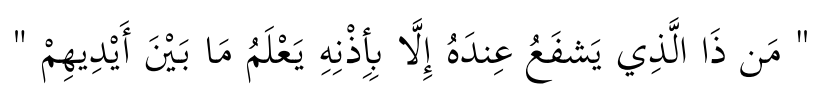

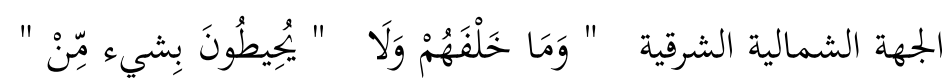

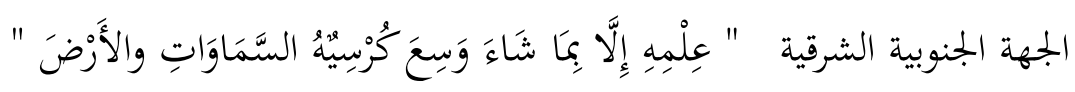

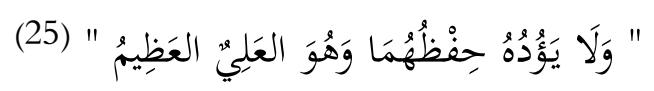

مضامين النصوص

\section{- علي تراكيب القبور:}

وقد جاء مضمون الكتابات علي هذه التراكيب التي تعلو القبور أما آيات قرآنية تبشر التبر

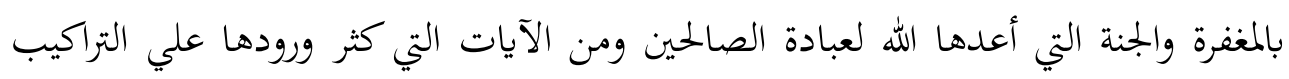

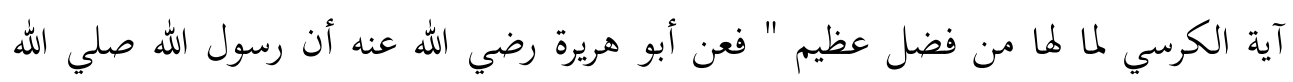

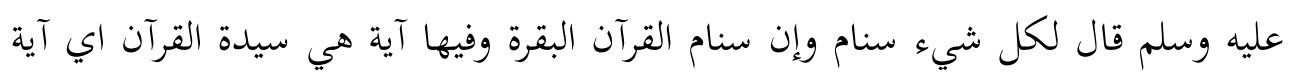


" الكتابات والنقوش الأثرية بمقبرة الحديوي إسماعيل وأمه خوشيار هانم بجامع الرفاعي "

الكرسي أخرجه الترمذي "(26) أو عبارات دعائية أو قصائد من الشعر كما ورد بالشاهد الذي يعلو تركيبة خوشيار هانم .

\section{- شواهد القبور}

نقشت معظمها بالخط الفارسي مثل شاهد تركيبة خوشيار هانم كما أصبح الشاهد يمدنا

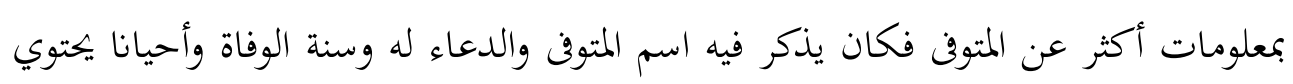
علي أبيات من الشعر وذكر تاريخ الوفاة بحساب الجمل في الشطر الأخير من البيت كما ذكر بتركيبة خوشيار هانم .

\section{أنواع الخطوط التي استعملت علي هذه التراكيب: -}

خط الثلث :

لعب خط الثلث في القرنين (9-8 هـ/ 14-15 م ) دورا هاما كخط تذكاري لا رسمي علي العمائر والتحف الفنية وشواهد القبور يفوق الدور الذي لعبه خط النسخ وذلك لان

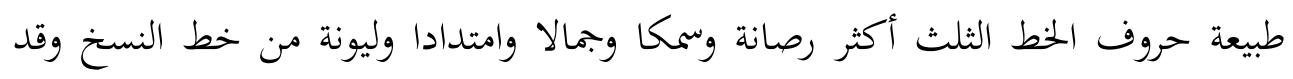
أضفت مظهر العظمة والفخامة التي تناسبت مع عظمة واجهة العمائر المشيدة في القرنين (8-9 هـ/14-15 م ) (27) واستخدم هذا الخط في تركيبة كلا من الخديوي إسماعيل بالمستوي الثاني وبالمستوي الأول والثاني بتركيبة خوشيار هانم

\section{الخط الكوفي ذو الأرضية النباتية :}

ويسمي أيضا الكوفي المخمل أو الكوفي المهاد الزخريف وتستقر فيه الكتابة فوق أرضية من سيقان النباتات أوراقها التي تشكل بطريقة تتخذ في مظهرها شكلا لولبيا ومن أشهر أمثلته في إيران وين غزنة وين جامع السلطان حسن بالقاهرة , ولحق بهذا النوع كتابات تختص فيها

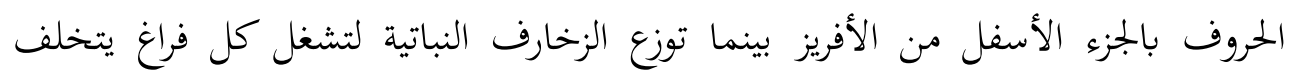

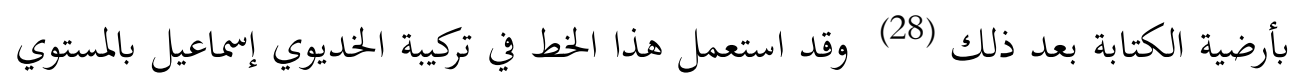




\section{الخطط النستعليق :}

تأتي تسمية هذا الخط في الأشعار والمرقعات القديمة هكذا " نسخ تعليق " أو " نسختعليق " وبعد ذلك خففت لسهولة الاستعمال وصارت التسمية " نستعليق " ويعرف هذا الخط بين الخطاطين الغير إيرانيين باسم الخط الفارسي كما هي الحال في مصر والبلاد العربية , وهي تسمية شاعت علي أساس أن هذا الخط قد ابتكر ووضعت قواعده في فارس الإسلامية ومنها انتشر إلي سائر البلاد في دار الإسلام وعليه فإن إطلاقها يعني هذا النوع من الخط

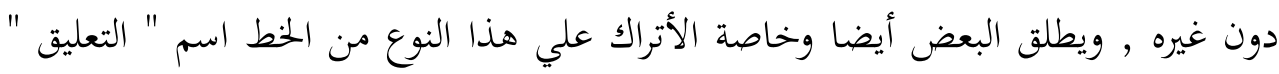

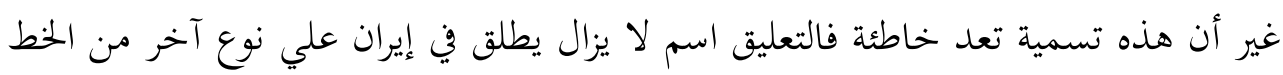
يختلف في هيئته وكتابته عن النستعليق (29)

ويكتب خط النستعليق بنفس سمك قلم الثلث ويسمي الدقيق منه في التركية " خردة (30) تعليق" والغليظ منه يسمي " جلي التعليق " وقد ورد هذا الخط علي شاهد القبرالذي يعلو تركيبة خوشيار هانم.

$\underline{ا ٔ ن و ا ع ~ ا ل م و ا د ~ ا ل خ ا م ~}$

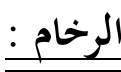

هو حجر جيري يقبل الصقل واستخدم في زخرفة العمائر لما له من أوصاف مطلوبة كالصلابة ودقة الحبوب والنقاوة وصفاء اللون والشفافية ومقاومة الحوادث الجوية , كما يعد الرخام أحد أهم الموارد التي استعملت في بجال تسجيل الكتابات الأثرية من العصريين المملوكي والعثماني , وساعد علي هذا المميزات الخاصة للرخام والمتمثلة في الصلادة النابتحة عن تكوينه الطبيعي , حيث أن التبلور الناتج من تأثير الضغط والحرارة أثناء تكونه في

الطبيعة يساعد علي زيادة حجم حبيباته وبحانسها وقلة مسامتها وزيادة تماسكها (31) ومن ثم أصبح الرخام بما تميز به من تلك الخصائص من أطول المواد الزخرفية عمراكما تميزت بعض أنواع الرخام بالمطاوعة وسهولة تفصيلها حسب الحجم المطلوب , وتميز بالجمال 
" الكتابات والنقوش الأثرية بمقبرة الحديوي إسماعيل وأمه خوشيار هانم بجامع الرفاعي "

الطبيعي والألوان البديعة ونعومة الملمس والبريق الطبيعي لأسطحه المصقولة إلي جانب سهولة تنظيفه مع ثبات لونه , وقد تعددت مسميات الرخام إما بتعلد ألوانه , أو لتعدد

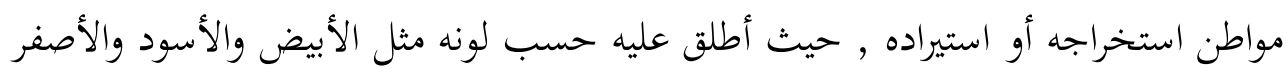
والأزرق والأحمر والأخضر المرسيني وغيرها من الأسماء (32). 
آسيا زعزوع هواري محمد

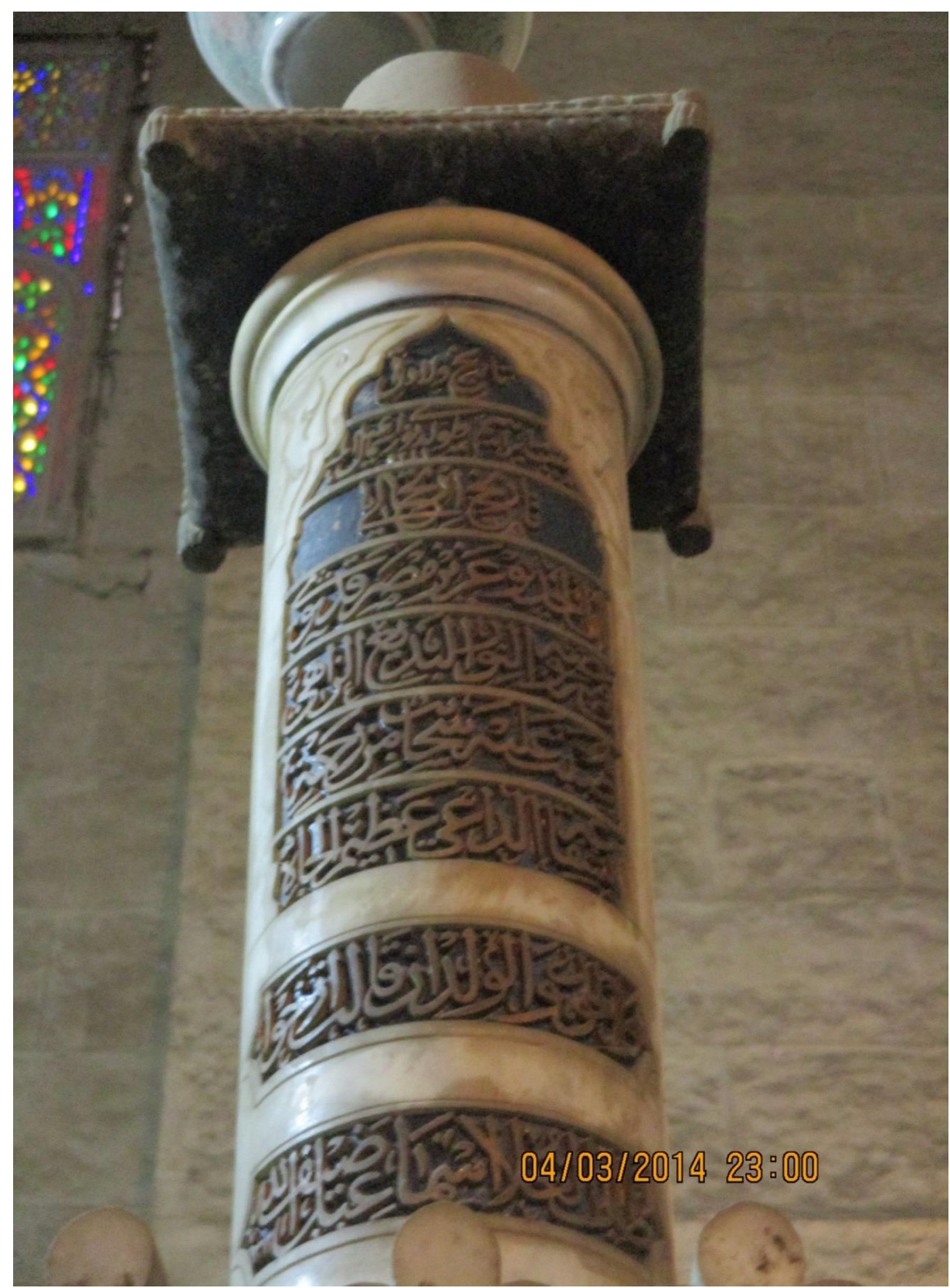


" الكتابات والنقوش الأثرية بمقبرة الحديوي إسماعيل وأمه خوشيار هانم بجامع الرفاعي "

$$
\text { شكل (1) : الشاهد الذي يعلو الجحانب الجنوبي الغربي من تركيبة الحديوي إسماعيل }
$$

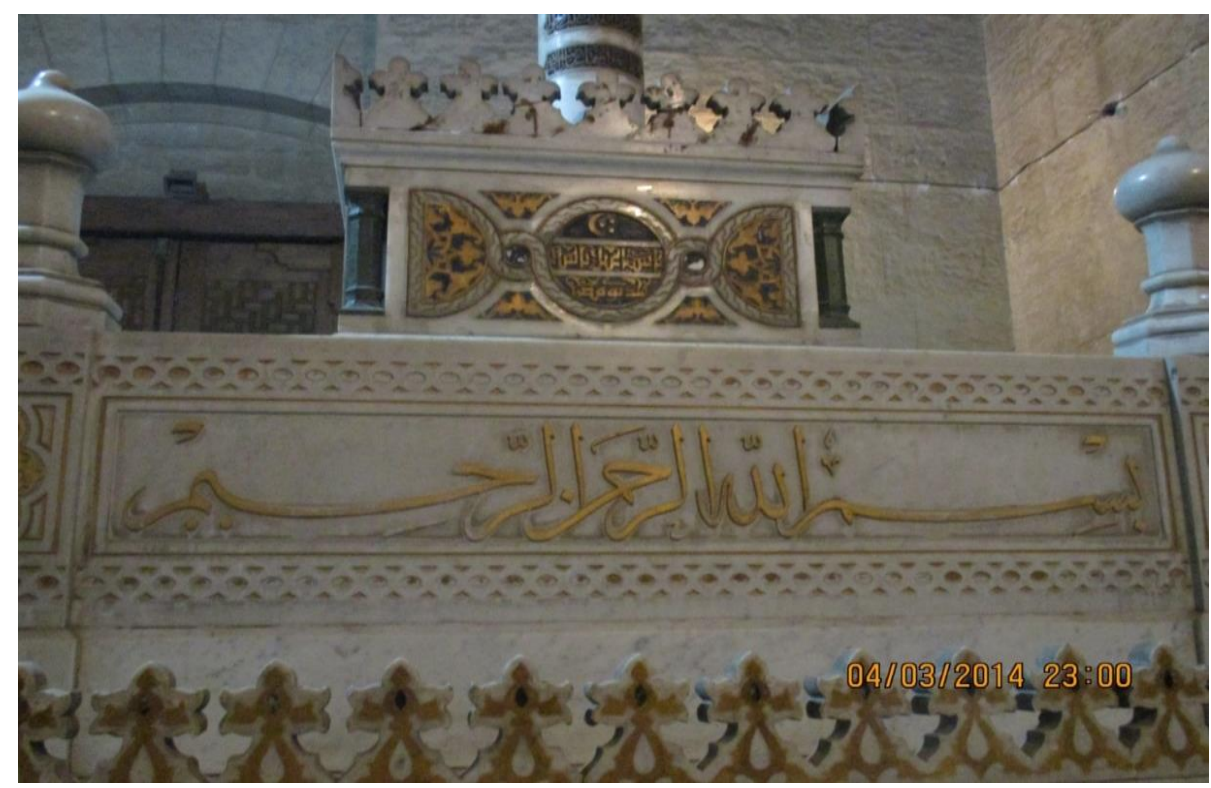

بالخط الثلث البارز سنة 1312 هـ/ 1894 م

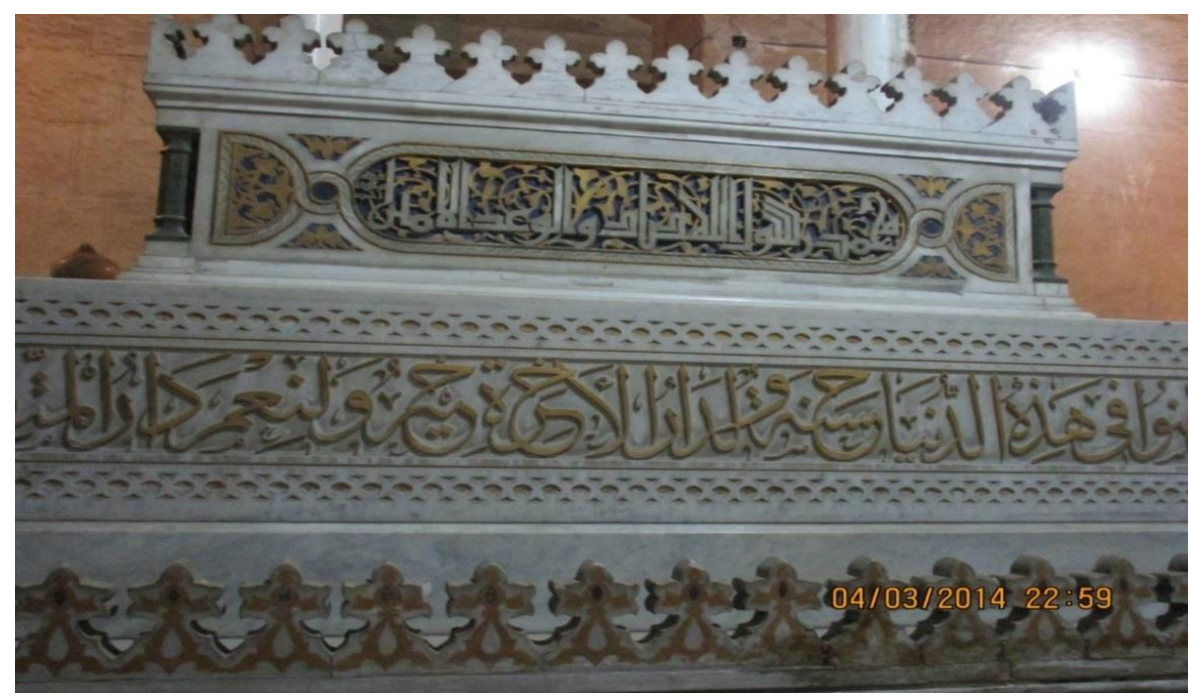



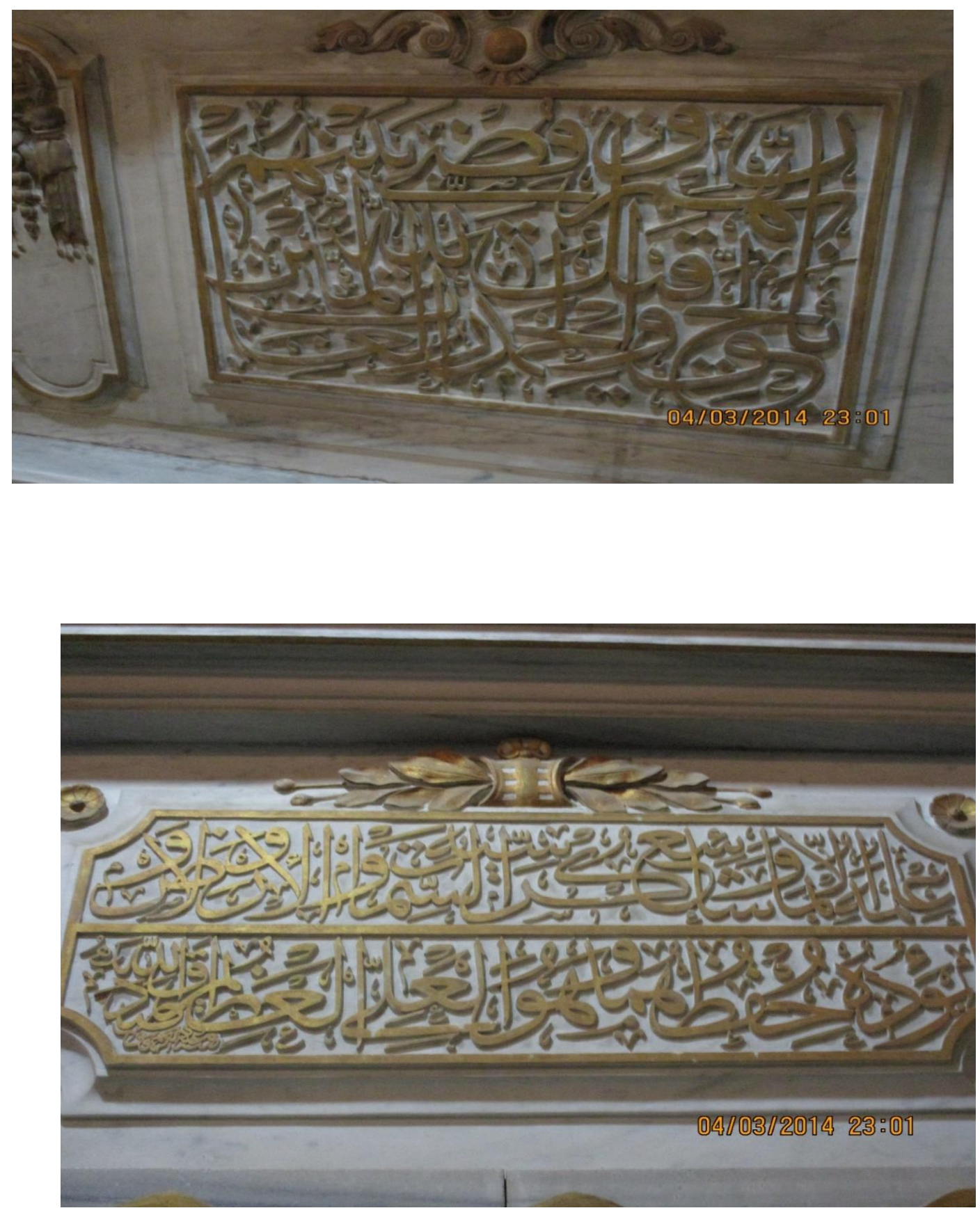
" الكتابات والنقوش الأثرية بمقبرة الخديوي إسماعيل وأمه خوشيار هانم بجامع الرفاعي "

شكل (3-2)- من كتابات تركيبة الحذديوي إسماعيل من الرخام بالحفر البارز

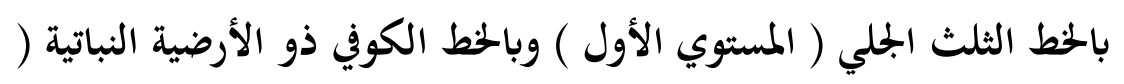

المستوي الثاني )

شكل (4) : من كتابات تركيبة خوشيار هانم بالخط الثلث الجلي البارز ( المستوي الأول

شكل (5): من كتابات المستوي الثاني لتركيبة خوشيار هانم بالحفر البارز بالخط الثلث

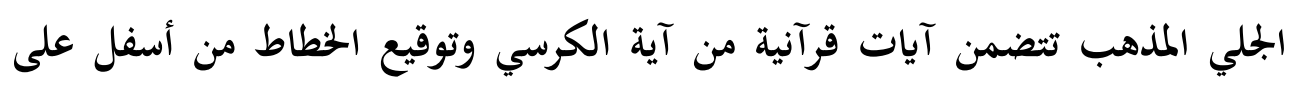
اليسار بصيغة " راقمه عبد الكريم فايق سنة 1303 هـ"

$\underline{\underline{ا ل خ ا ت م ة ~}}$

تناول هذا البحث إحصاء كتابات تراكيب المقابر وتسجيلها لكل من الخديوي إسماعيل وأمه خوشيار هانم بالجانب الشمالي الشرقي بجامع الرفاعي , وقد قمت بوصف هذه الكتابات

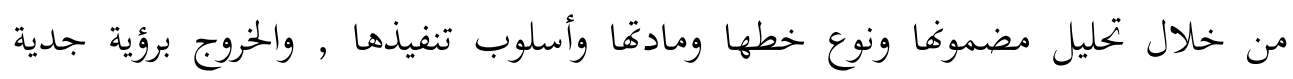
لمضامين تلك النصوص تتخلص في أها كانت ترجمة صادقة للفكر الإسلامي وصدي ومادي وناسي واضحاً للعقيدة الإسلامية الراسخة في نفس المسلم مما كان له انعكاساته الواضحة علي

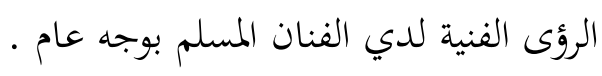

وأوضحت دراسة البحث النصوص القرآنية والتركيز عليها لما لها أثر عظيم للمتوفي , حيث

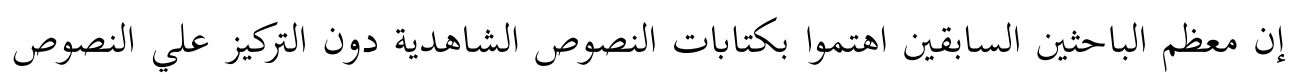

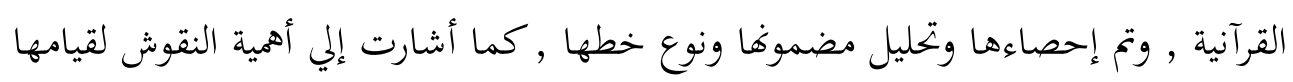
بلدور إعلامي سياسي وديني , فهي تحدد تاريخ الإنشاء وتاريخ الولادة وتاريخ الوفاة واسم

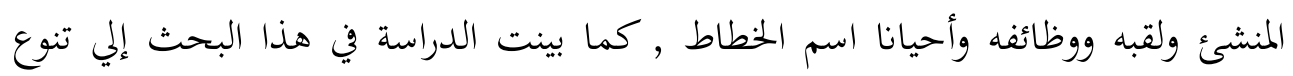
النقوش مابين نقوش شاهدية ونقوش زخرفية وقرآنية وتنوع المواضيع التي نفذت علين وليها 
الكتابات علي هذه المقابر مثل الشواهد والقواعد الرخامية , وفي النهاية أمدتنا نقوش هذا البحث بمعلومات قيمة عن ما جاء في كتب المصادر الأدبية بنوعيها المختلفة وبخاصة المصادر التاريخية وذلك بتأكيدها أو بنفيها أو تكون قرينة لها .

\section{قائمة المصادر والمراجع}

(1 ) محمود محمد فتحي الألفي : العمارة الإسلامية في مصر خلال القرن 19 عشر أسرة محمد علي بالقاهرة " رسالة دكتوراة غير منشورة , جامعة

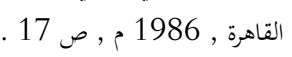

(2 ) فادية عطية مصطفي : عمائر القاهرة الجنائزية خلال القرن 13هـ / 19 م م" دراسة أثرية معمارية " كلية الأثار , جامعة القاهرة , 2003 م م ,

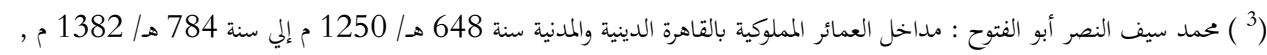

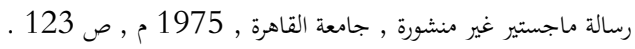

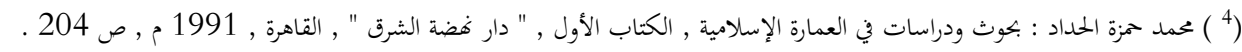

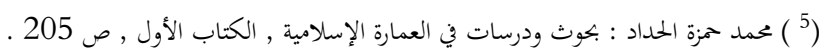

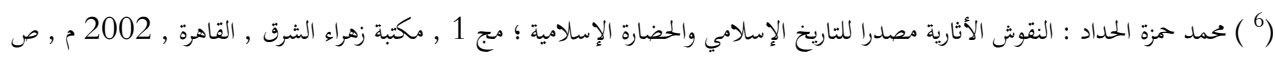

.19-16

. فادية عطية : عمائر القاهرة الجنائزية , ص 277 .

$\left({ }^{8}\right)$ Deleon, N, Edwim , Egypt under its Khedives ar , the old hause af Bondoage under mosters - , William cloutes and sons limited, olandon, 1882 p. 96-97 .

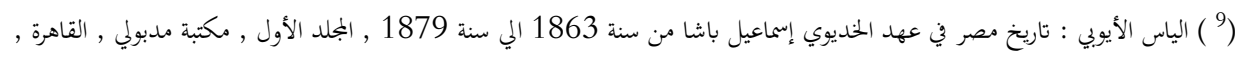

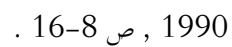

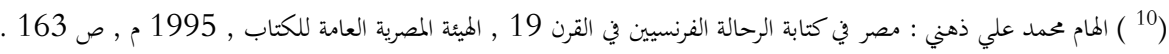

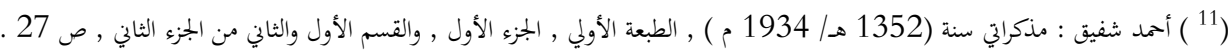

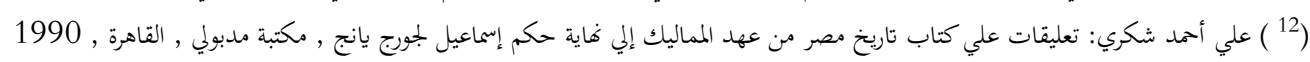

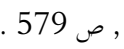

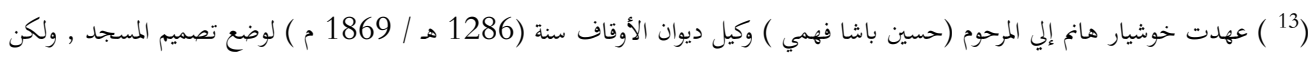

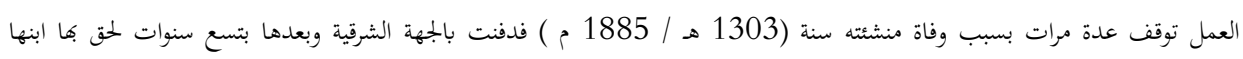

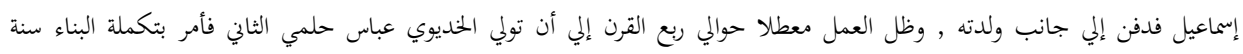

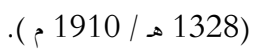

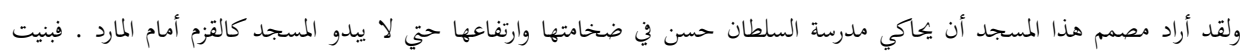

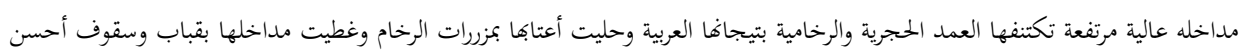

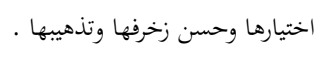

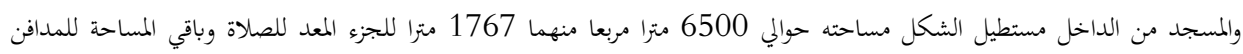

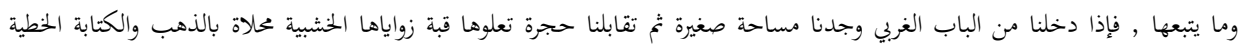

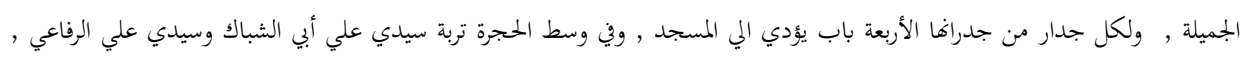

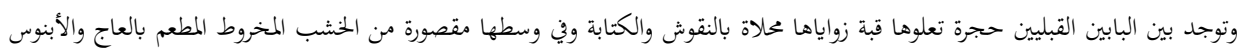
أقيمت علي ضريح سيدي علي الأنصاري . 


\section{" الكتابات والنقوش الأثرية بمقبرة الحديوي إسماعيل وأمه خوشيار هانم بجامع الرفاعي "}

ومحراب المسجد يقع في وسط الجدار الشرقي وقد غشي بالرخام الملون ويكتنفه أربعة أعمدة رخامية , وبيانب المراب يوجد المنبر من الحشب النقي

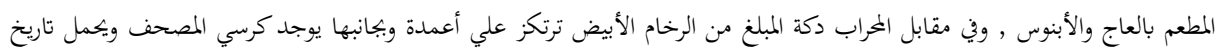

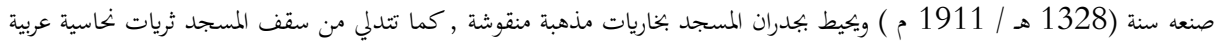

ومشكاوات زجاجية موهة بلمنيا . المان.

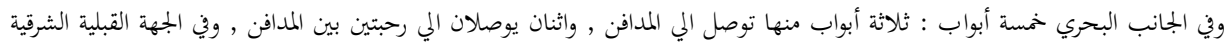

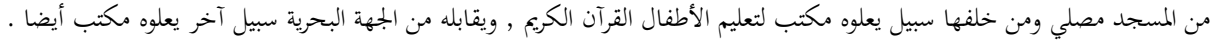

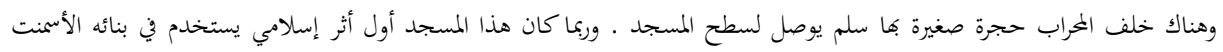

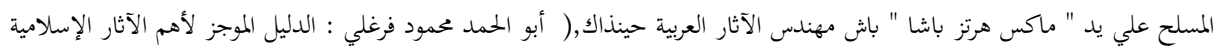

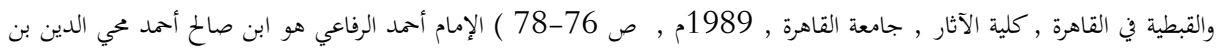

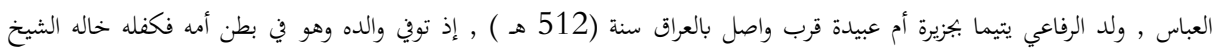

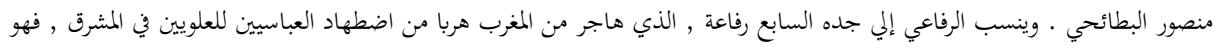

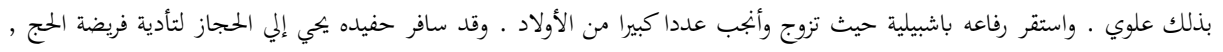

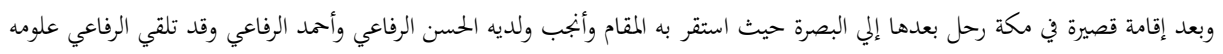

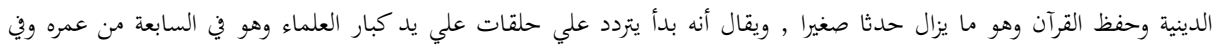

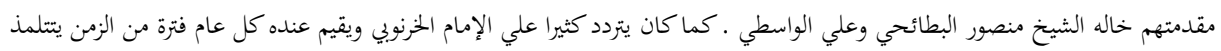

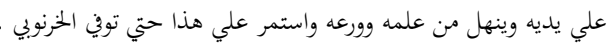

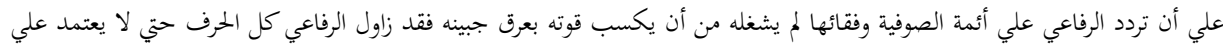

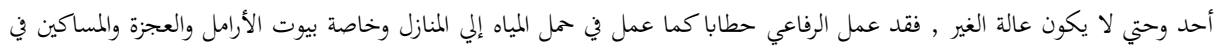

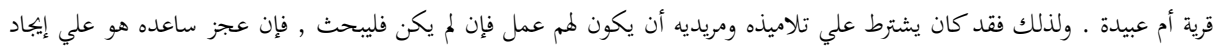

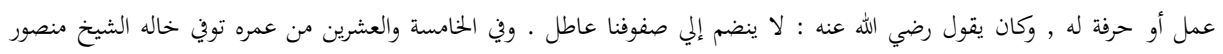

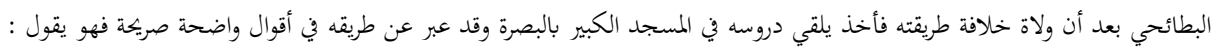

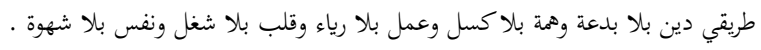

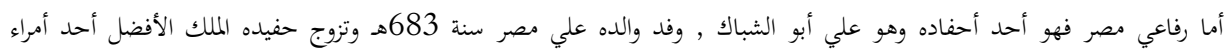

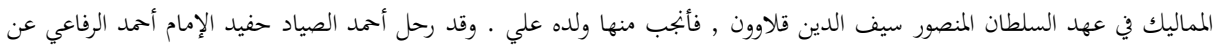

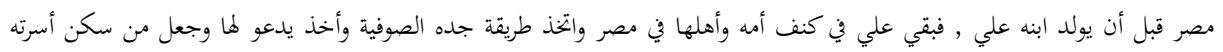

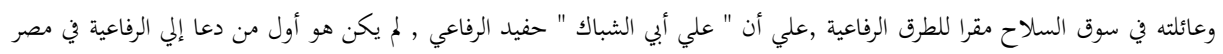

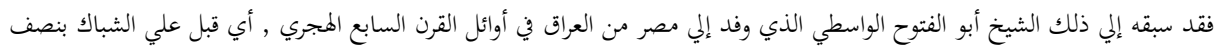

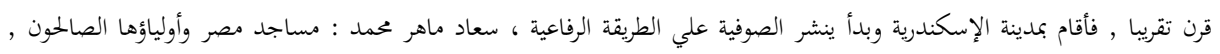

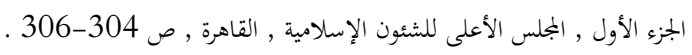
(14 ) مصطفي بركات محسن علي : النقوش الكتابية علي عمائر مدينة القاهرة في القرن التاسع عشر , دراسة فنية أثرية , رسالة دكتوراه غير منشورة , كلية الآثار , جامعة القاهرة , 1991 , ص ص ع 4 . 4. (15)

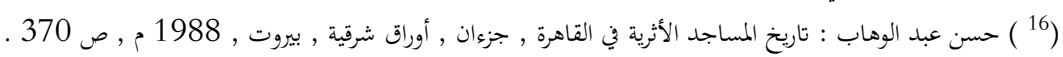

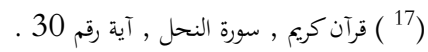

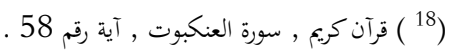

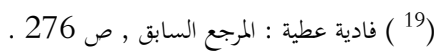


(20) خوشيار هانم : والدة المديوي إسماعيل كان لما غرام بالفن الجميل وكانت تتنقي الجواري الحسان وتأتي لهن بالمعلمين والمعلمات مصريين وأتراكا

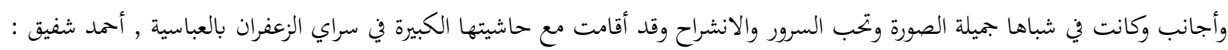

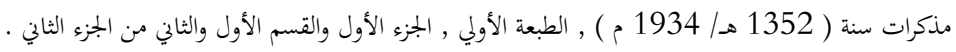

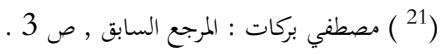

(22 ) ذكرت الباحثة فادية عطية - عمائر القاهرة الجنائزية , ص صركات : 273 الآيات ولم تذكر الكتابات , وهذه الكتابات قمت بقرأتحا بنفسي من علي

$$
\text { التركيبة . }
$$

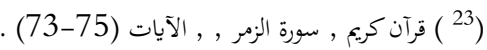

$$
\begin{aligned}
& \text { (24) هذه الكتابات قمت بنفسي بقراءما من علي التركيبة . }
\end{aligned}
$$

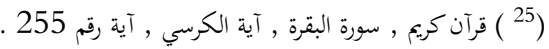

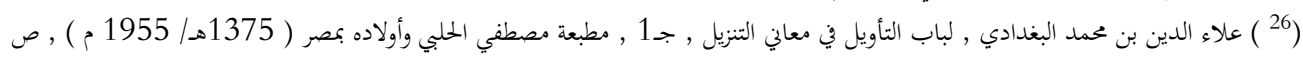

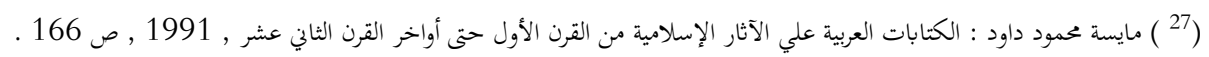

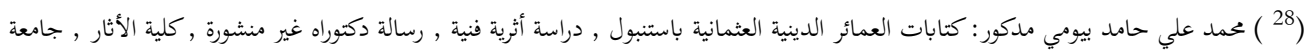

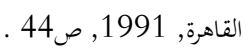

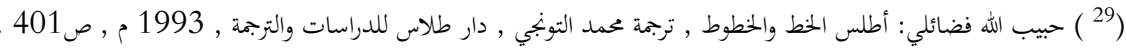

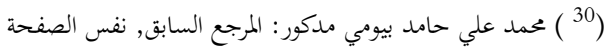

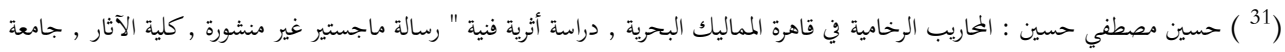

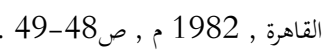

( 32 ) حمد عارف : خلاصة الأفكار في فن المعمار , القاهرة , بولاق , 1897 م , ص ص 71 . 1982. 